\title{
Removal of Hardness using Coconut Shell Carbon
}

\author{
Shemeera K H, N. Indubhavani, B. Hemalatha, B. Laksmivijayadurga
}

\begin{abstract}
Water contamination is an ongoing issue around the world, especially for poor people, who mostly depend on ground water as their source of drinking water. Coconut shells can be used as a material for softening as it is an easily available source of activated carbon. It is proved that it can make water safe and improve the taste of it by adsorbing heavy metals and toxic organic chemicals like pesticides. Coconut shell carbon (CSC) can also remove odor and turbidity of by removing certain suspended and dissolved solids. The present study aims to remove hardness present in water using coconut shell powder. Batch experiments were carried using varying concentrations of adsorbent dose at different contact time in order to reduce hardness present in the water sample. Optimum adsorbent dosage and optimum contact time were determined for maximum removal efficiency. This project succeeds by developing a low cost user friendly water treatment technique to rural people who faces the problem with hard water using locally available waste material like coconut shell.
\end{abstract}

Index Terms: Adsorption, coconut shell carbon, hardness, softening

\section{INTRODUCTION}

Calcium and Magnesium salts are water contaminants of the great concern as they impart hardness to water .Hardness problem is affecting various places across the world. Coastal regions are mostly affected by hardness since rock which is rich in Calcium and Magnesium ions can easily dissolve into the groundwater to make it hard[3,4]. By definition, water hardness is due to the presence of multivalent metallic cations ,mainly calcium and magnesium [2].In daily uses, hard water is associated with number of problems such as difficulty in giving lather with soap, scales formation in pipes, boilers, washing machines, spots on sinks and clothes and also results in toughening of hair and skin [5,6]. It is also reported that continuous usage of hard water is likely to cause serious health issues such as cancer, cardiovascular disorder and kidney stones [1].

Softening is a topic of ongoing research as there are huge problems associated with hardness in water. been put in place to soften the water. Ion exchange, chemical precipitation, membrane filtration and electro based techniques are some of

Revised Version Manuscript Received on August 19, 2019.

Shemeera K H, Assistant professor, Rajiv Gandhi University of Knowledge Technologies, IIIT Nuzvid, Andhra Pradesh, India.(email: shemm008@gmail.com)

N. Indubhavani, Under graduate student, Rajiv Gandhi University of Knowledge Technologies, IIIT Nuzvid, Andhra Pradesh, India.(email: sivabhavaninallmothu@gmail.com)

B. Hemalatha, Under graduate student, Rajiv Gandhi University of Knowledge Technologies, IIIT Nuzvid, Andhra Pradesh, India.(email: boyinahemalatha401@gmail.com)

B. Laksmivijayadurga, Under graduate student, Rajiv Gandhi University of Knowledge Technologies, IIIT Nuzvid, Andhra Pradesh, India. (email: n140312@rguktn.ac.in)
them[1].However, these process needs high cost in installation and maintenance[7]. Adsorption method of softening using activated carbon from agricultural wastes like coconut shells is having high potential because they are locally and cheaply available. Activated carbon can be generated from these wastes and it can be used to treat water [8]. In the present paper, coconut shell carbon (CSC) in powder form is being tested to establish its performance in softening hard water.

\section{MATERIALS AND METHODS}

Material used for removing hardness coconut shell carbon powder .It was prepared in the laboratory by burning of coconut shells and powdering them to particle size of about 2 $\mathrm{mm}$ diameter. It acted as an adsorbent for multivalent metallic cations.

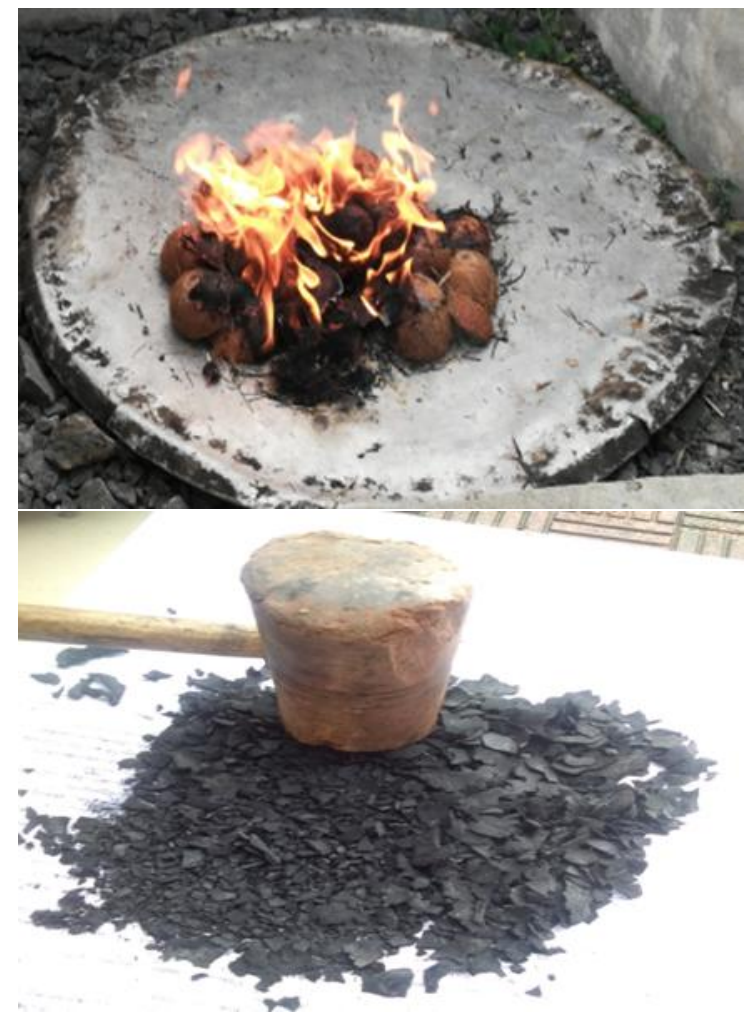

Figure 1. Preparation of CSAC powder

Synthetic hard water for experimental analysis was prepared by dissolving appropriate concentrations of $\mathrm{CaCl} 2$ and $\mathrm{MgSO} 4$ in distilled water. EDTA titration method was used for measuring the hardness. 
Adsorption behavior of CSC was studied by conducting batch adsorption experiments on hardness removal under different adsorption condition. Adsorption capacity was examined in different conditions varying dosage of adsorbent, contact time and mixing rate.

In order to find the optimum adsorbent dosage, different dosages of CSC powder were added to hard water $(5 \mathrm{~g}, 10 \mathrm{~g}$ and $15 \mathrm{~g}$ ) and the solution was mixed at $100 \mathrm{rpm}$ for $1 \mathrm{~min}$ and 20rpm for 30min.Hardness was checked after filtering and hardness vs. adsorbent dosage was plotted in fig.2. Percentage removal of hardness was also plotted against adsorbent dosage in fig. 3 .

\section{B. Procedure for Optimum contact time}

Optimum Contact time was determined by continuously monitoring the hourly variation in hardness of $100 \mathrm{ml}$ water which was mixed at $100 \mathrm{rpm}$ for $1 \mathrm{~min}$ and $20 \mathrm{rpm}$ for $30 \mathrm{~min}$ after adding $10 \mathrm{~g}$ CSC powder. Hardness was checked after filtering and its variation with respect to contact time is shown in fig. 6. Fig. 7 depicts how percentage removal of hardness varies against contact time.

\section{RESULTS AND DISCUSSIONS}

\section{A. Optimum Adsorbent dosage}

Optimum adsorbent dosage was determined in two steps. In first stage, different dosages of CSC powder were added to hard water $(5 \mathrm{~g}, 10 \mathrm{~g}$ and $15 \mathrm{~g})$ and the solution was mixed at $100 \mathrm{rpm}$ for $1 \mathrm{~min}$ and $20 \mathrm{rpm}$ for $30 \mathrm{~min}$.It was observed from hardness VS adsorbent dosage graph that maximum percentage of hardness was removed for a dosage of $10 \mathrm{~g}$ and approximately similar percentage was observed for $15 \mathrm{~g}$ also. In second stage, percentage of removal of hardness was further tested for dosages of 10,11,12,13, 14 and 15 for obtaining the optimum dosage (fig. 4). Results shown in figure 5 shows that percentage of hardness removal is high when $10 \mathrm{~g}$ and $11 \mathrm{~g}$ were added. $66.79 \%$ hardness is removed for a dosage of $10 \mathrm{~g}$ and for $11 \mathrm{~g}$ it is $69.72 \%$. Hardness removal further decreased beyond this and solution turns yellow color above dosage of ten. So it was concluded that optimum dosage is $100 \mathrm{~g}$ per liter of water.

Figure 2. Adsorbent dose Vs Hardness

\section{A. Procedure for Optimum Adsorbent dosage}
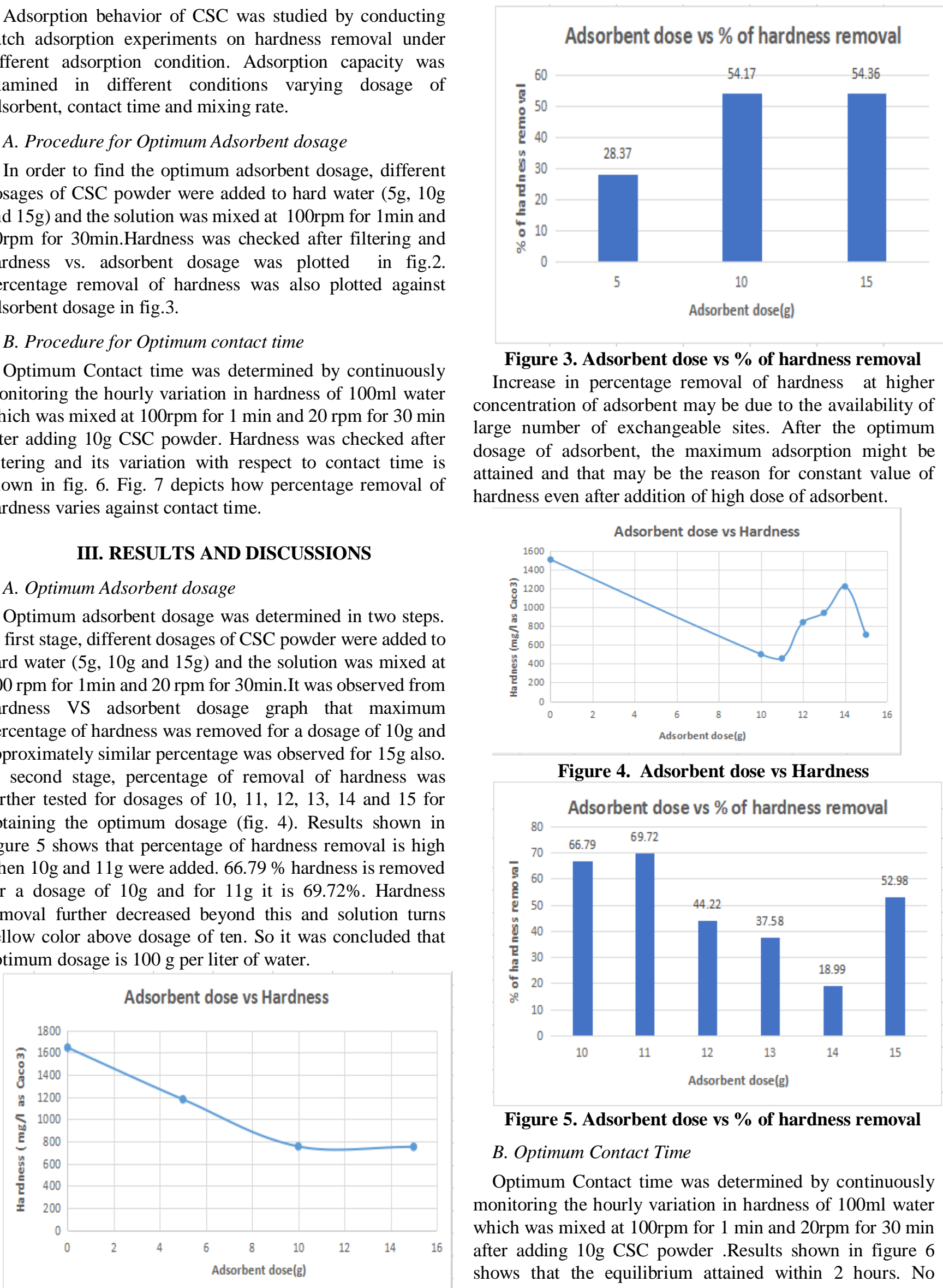

Figure 3. Adsorbent dose vs \% of hardness removal

Increase in percentage removal of hardness at higher concentration of adsorbent may be due to the availability of large number of exchangeable sites. After the optimum dosage of adsorbent, the maximum adsorption might be attained and that may be the reason for constant value of hardness even after addition of high dose of adsorbent.

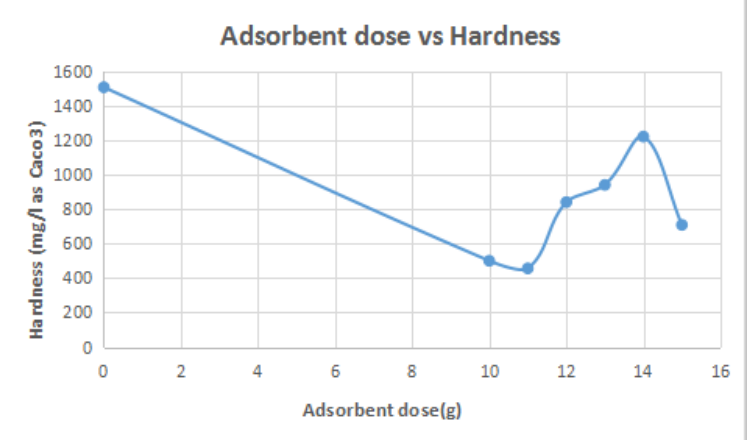

Figure 4. Adsorbent dose vs Hardness

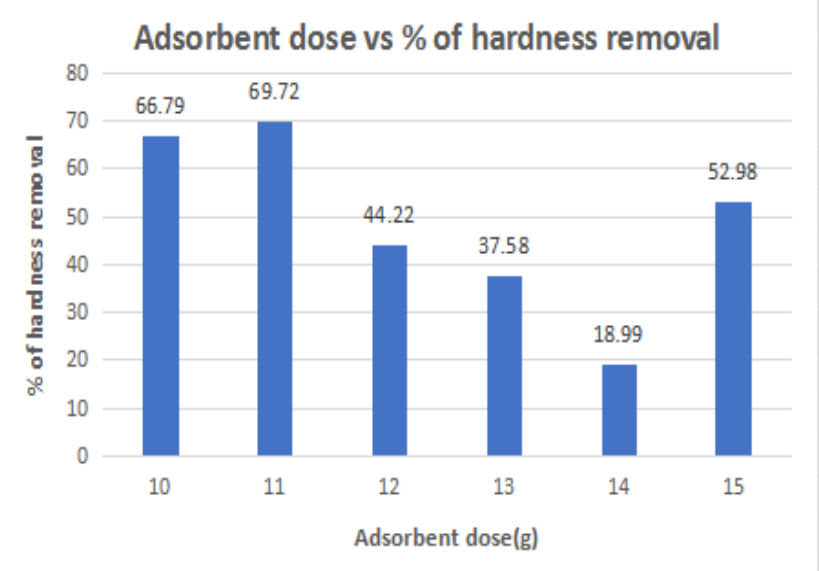

Figure 5. Adsorbent dose vs \% of hardness removal

\section{B. Optimum Contact Time}

Optimum Contact time was determined by continuously monitoring the hourly variation in hardness of $100 \mathrm{ml}$ water which was mixed at 100rpm for $1 \mathrm{~min}$ and $20 \mathrm{rpm}$ for $30 \mathrm{~min}$ after adding 10g CSC powder .Results shown in figure 6 shows that the equilibrium attained within 2 hours. No significant change was observed after increasing the contact time. 


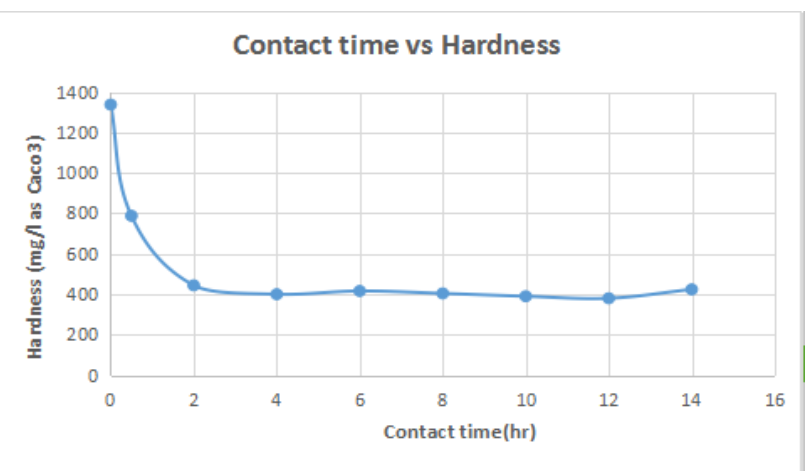

Figure 6. Contact time vs Hardness

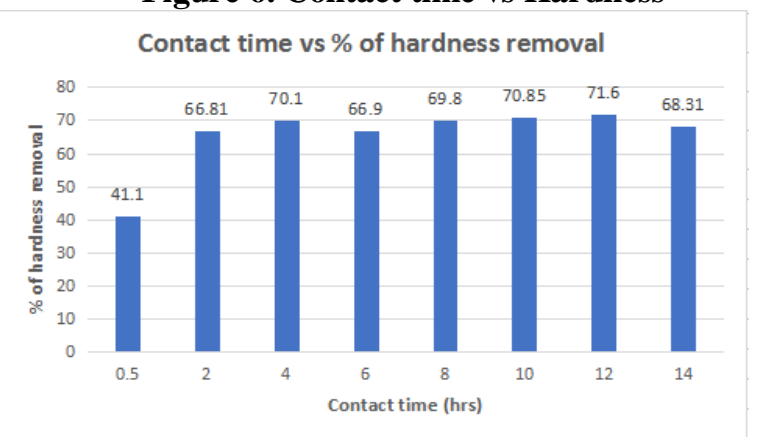

Figure 7.Contact time vs \% of hardness removal

This is due to the fact that, there is availability of more number of vacant adsorption sites during the initial stage and .However the increased repulsive forces between multivalent metallic cations like Calcium and Magnesium ions on solid phase and liquid phase with the passage of time add difficultness, for further adsorption on remaining vacant surface sites.

\section{CONCLUSION}

This paper mainly concentrates to obtain low cost water treatment using coconut shell activated carbon which is easily available, especially in coastal regions where hardness problem is the challenging issue. The removal of hardness using coconut shell activated carbon is investigated by conducting laboratory tests. Optimum adsorbent dosage and optimum contact time were determined by batch experiments for obtaining maximum removal efficiency. Maximum hardness removed was $70.1 \%$ and it was achieved using an adsorbent dosage of $100 \mathrm{~g}$ per liter of water with contact time of 4 hours. The major success of this project is the development of a low cost and user friendly water treatment technique to people who faces the issues with hard water.

\section{REFERENCES}

1. Cecilia Rolence, Revocatus Lazaro Machunda, Karoli Nicholas Njau. "Water hardness removal by coconut shell activated carbon", Department of Water and Environmental Science and Engineering, Nelson Mandela African Institution of Science and Technology (NM-AIST), Arusha, Tanzania , 2014.

2. K. S. Meena, R. K. Gunsaria, K. Meena, N. Kumar and P. L. Meena, "The problem of hardness in ground water of Deoli Tehsil (Tonk District) Rajasthan", Journal of Current Chemical \& Pharmaceutical Sciences, 2(1): 50-54, 2011.

3. S. M . Knivsland, "Water chemistry in the Bahi-Manyoni Basin in Tanzania", Reprosentralen, University of Oslo, 2012.

4. Z. A. Napacho and S. V. Manyele, "Quality Assessment of Drinking Water in Temeke District (part II): Characterization of Chemical Parameters", African Journal of Environmental Science and Technology, 4(11): 775-789, 2010.

5. S. J. Seo, H. Jeon, L. K. Lee, G. Y. Kim, D. Park, H Nojima, J. Lee and S. Hyeon, "Investigation on removal of hardness ions by capacitive deionization (CDI) for water softening applications", Water research, 44: 2267-2275, 2010.

6. R. Johnson and T. Scherer, "Drinking water quality testing and interpreting your results", NDSU Extension Service, 2012.

7. Frankel, V. S. "Seawater desalination: trends and technologies”. USA: Kennedy/Jenks Consultants, 2011.

8. M. Grassi, G. Kaykioglu, V. Belgiorno and G. Lofrano, "Removal of emerging contaminants from water and wastewater by adsorption process", In Emerging Compounds Removal from Wastewater (pp. 15-37). Springer, Netherlands, 2012. 